\title{
Avaliação de um Esquema de Seleção para Bovinos Zebus de Dupla Aptidão1
}

\author{
Raimundo Nonato Braga Lôbo², Vânia Maldini Penna ${ }^{3}$, Fernando Enrique Madalena
}

\begin{abstract}
RESUMO - Um enfoque determinístico foi utilizado para a predição do ganho genético e do valor presente líquido de um programa de seleção para uma população de bovinos zebus de dupla aptidão, envolvendo, como critério, pesos corporais, produção de leite e características de fertilidade. Foram verificados altos ganhos e lucro genéticos. Mais de $70 \%$ do lucro genético corresponderam ao valor presente líquido, justificando o custo de seleção. Este lucro pode ser explicado pelo número reduzido de animais em que as mensurações foram realizadas em relação ao benefício populacional do melhoramento e pelos altos pesos econômicos das características selecionadas.
\end{abstract}

Palavras chave: dupla aptidão, ganho e lucro genético, seleção, valor presente líquido, zebu

\section{Breeding Program Evaluation for Dual Purpose Zebu Cattle}

\begin{abstract}
A deterministic approach was used to predict genetic gain and net present value for a breeding program in a dualpurpose zebu cattle population. The considered criterias were body weights, dairy and reproductive traits. High genetic gains and profit were obtained. More than $70 \%$ of genetic profit was net present value, justifying selection costs. The small proportion of recorded animals in relationship to the beneficial population of the improvement and the high economic values of traits could explain this profit.
\end{abstract}

Key Words: breeding program, dual-purpose cattle, genetic gain and profit, net present value, zebu

\section{Introdução}

No Brasil, um setor dos produtores utiliza animais zebuínos e/ou seus mestiços para a produção de leite, sendo que machos e fêmeas excedentes e vacas de descarte são comercializados para produção de carne. A seleção simultânea para produção de carne e leite e o desenvolvimento de programas de melhoramento que satisfaçam ambos os objetivos podem ser importantes para o melhoramento destas raças e para considerável parte dos criadores em nosso país.

A proposta de um programa de melhoramento para bovinos de dupla aptidão no Brasil tem sido pouco considerada. Por outro lado, a maioria das pesquisas desenvolvidas nesse país diz respeito aos métodos de avaliação genética e à natureza das respostas a seleção.

O mais eficiente programa de melhoramento é aquele que maximiza o lucro do investimento, o qual não é completamente proporcional ao ganho genético, apesar de haver maiores ingressos, quando se produz mais. Dessa forma, avaliações econômicas, assim como avaliações genéticas, são necessárias para a condução racional e eficiente destes programas.
Este estudo teve o objetivo de elaborar um programa de seleção otimizado para bovinos de dupla aptidão, envolvendo, como critérios, características de peso, produção de leite e fertilidade, sendo considerada para este propósito uma estrutura de população representativa da produção nacional, tomandose como modelo a raça Guzerá e seus cruzamentos.

\section{Material e Métodos}

As avaliações foram realizadas por meio do aplicativo ZPLAN, escrito por KARRAS (1984) e, posteriormente, desenvolvido por NIEBEL, como descrito por NIEBEL e FEWSON (1988) e KARRAS et al. (1993).

O ZPLAN determina o critério de seleção que otimiza o valor presente líquido do programa de melhoramento, inclusive para população dividida em estratos, e estima ganhos genéticos, receitas e lucro decorrentes da seleção por intermédio de enfoque determinístico, utilizando a teoria dos índices de seleção e a metodologia do fluxo de genes descontado. A partir de parâmetros zootécnicos (reprodutivos e

\footnotetext{
1 Parte da Tese do primeiro autor, apresentada a Escola de Veterinária da Universidade Federal de Minas Gerais para obtenção do título de Doutor em Ciência Animal.

2 Departamento de Zootecnia da Universidade Federal do Ceará, Caixa Postal 12167, CEP 60021-970 Fortaleza - CE. E-mail: nordeste@ufc.br

3 Professor do Departamento de Zootecnia da Escola de Veterinária da Universidade Federal de Minas Gerais, Caixa Postal 567, CEP 30161 970, Belo Horizonte - MG. E-mail: vania@vet.ufmg.br e fermadal@dedalus.lcc.ufmg.br
} 
vida útil), genéticos e econômicos e da estrutura da população fornecidos pelo usuário, ZPLAN calcula a intensidade de seleção, o ganho genético anual, a resposta genética total na população, as expressões descontadas, os custos e o lucro do programa de seleção, segundo descrição de NITTER et al. (1994). Dois tipos de lucro são calculados: o lucro genético, “o valor monetário da mudança genética expressa pelos animais melhorados durante o período do investimento", e o lucro do programa de seleção, ou valor presente líquido do mesmo, obtido subtraindo do lucro genético o custo do programa.

\section{Estrutura da população e grupos de seleção}

A estrutura da população foi determinada buscando representar a raça Guzerá e seus mestiços. Considerou-se população total de 95.000 vacas, dividida em três estratos: um núcleo (Estrato 1), de 1.000 vacas puras, que possuíam registros de produção para características leiteiras, reprodutivas e de peso corporal; o Estrato 2, multiplicador, com 9.000 vacas puras, apresentando registros somente para características de peso corporal e reprodutivas; e o Estrato 3, de 85.000 vacas comerciais, mestiças, sem registros de produção. O número de vacas em cada estrato foi estabelecido de acordo com o número de animais Guzerá registrados e de doses de sêmen comercializadas (LÔBO, 1999).

Foram considerados 18 grupos de seleção, correspondentes aos diferentes grupos de machos e fêmeas selecionados em cada estrato (Figura 1). Touros provados (TP) e jovens (TJ, em teste) do Estrato 1 foram utilizados por meio da inseminação artificial, em 100, 20 e 11\%, respectivamente, das vacas dos estratos 1,2 e 3 . Os touros jovens tinham sua progênie testada nos estratos 1 e 2 (neste último apenas para pesos e fertilidade). A utilização de $11 \%$ de IA nas fazendas leiteiras foi baseada em levantamento do SEBRAE - MG (1996), enquanto o percentual no Estrato 2 foi determinado por intermédio de consultas com diversos criadores e o do Estrato 1 foi prefixado. Touros do Estrato 1 passavam para o Estrato 2, e touros do Estrato 2 para o Estrato 3, mas não foi considerada a passagem de fêmeas dos estratos $1 \mathrm{ou}$ 2 para o estrato inferior.

Estrato 1. O ZPLAN otimiza o número de touros em teste e o número de progênies de cada touro, a partir dos parâmetros reprodutivos e de sobrevivência fornecidos e do número de vacas a ser atendido por estes touros. A cada ano, eram testados 18 touros jovens do estrato 1 , filhos dos dois melhores touros

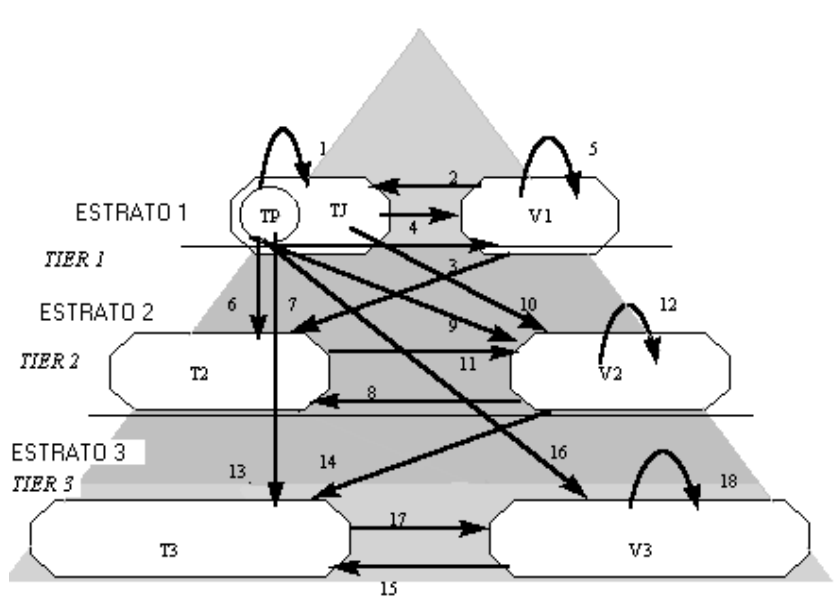

Figura 1 - Fluxo de genes, grupos de seleção (de 1 a 18) e estrutura da população considerada.

Figure 1 - Gene flow, selection groups (1 to 18) and population structure considered.

provados e das melhores vacas do mesmo estrato. Cada touro era testado com 20 filhas no estrato 1 e 20 progênies de ambos sexos no estrato 2 , neste apenas para avaliação de peso e reprodução. Os touros provados permaneciam dois anos em serviço no estrato 1 e o dobro nos estratos 2 e 3 .

As novilhas de reposição do estrato 1 eram filhas de touros provados e touros jovens em teste, recebendo, respectivamente, 35 e $15 \%$ de seus genes daqueles grupos e 50\% restantes de seus genes provenientes das melhores vacas do estrato 1 .

Estrato 2. Neste estrato, $20 \%$ das vacas eram inseminadas com sêmen de touros do estrato $1(18,4 \%$ com touros provados e 1,6\% com touros jovens em teste); $10 \%$ eram cobertas com touros provenientes do estrato 1 , filhos de touros provados e de vacas nãousadas como mães de touros do estrato 1 , sendo as segundas melhores após a seleção daquelas vacas; $20 \%$ eram cobertas em monta natural com touros nascidos no próprio estrato 2 , filhos de touros provados e vacas selecionadas por peso; e as $50 \%$ restantes eram cobertas com touros filhos de animais nãoselecionados, considerados de valor genético igual a zero. As novilhas de reposição do estrato 2 eram selecionadas apenas por peso e fertilidade.

Estrato 3. Neste estrato, utilizou-se sêmen de touros provados (TP) do Estrato $1 \mathrm{em} 11 \%$ das vacas, enquanto as $89 \%$ restantes foram cobertas por touros nascidos no próprio estrato, filhos dos TP e mães não-selecionadas $(12,3 \%)$, por touros provenientes do estrato 2 , filhos de touros prova- 
dos e vacas do estrato 2 não-selecionadas (10\%), e por touros não-provenientes dos estratos 1 e 2 , não-selecionados e considerados com valor genético igual a zero $(66,7 \%)$.

\section{Objetivo da seleção}

Para simular o sistema de produção de carne e leite com animais de dupla aptidão, tomou-se como base, para produção de leite, a fazenda demonstrativa da EPAMIG em Prudente de Moraes, MG, cujo desempenho zootécnico e econômico é conhecido detalhadamente (FERREIRA e FERREIRA, 1998, VERCESI FILHO et al., 2000). Como naquela fazenda os machos são abatidos com poucos dias de vida, para a recria e engorda tomou-se como base o sistema de produtividade média descrito no FNP - ANUALPEC 97, no qual $36 \%$ dos machos foram abatidos com 16 arrobas aos 30 meses de idade e 64\%, com 18 arrobas aos 42 meses de idade.

O objetivo da produção de leite incluiu as seguintes características (VERCESI FILHO et al., 2000):

PL - Produção de leite $(\mathrm{kg})$;

PG - Produção de gordura $(\mathrm{kg})$;

MAM - Casos de mamite;

FL - Fluxo lácteo (kg/min);

NSC - Número de serviços por concepção;

IPP - Idade ao primeiro parto (dias);

VU - Vida útil (anos);

PVA - Peso da vaca adulta $(\mathrm{kg})$.

A estas variáveis foi acrescentado o peso ao abate dos machos (PA, kg).

\section{Critérios de seleção}

Como critérios de seleção, foram utilizados índices (otimizados pelo ZPLAN) de algumas das seguintes características, dependendo do grupo de seleção considerado: pesos aos 205 (P205), 365 (P365) e 550 (P550) dias de idade, peso da vaca adulta (PVA), produção de leite (PL), produção de gordura (PG), duração de lactação (DL), idade ao primeiro parto (IPP), perímetro escrotal (PE) aos 365 dias de idade e número de serviços por concepção (NSC).

Cinco índices foram elaborados, para a seleção de touros provados, touros jovens, vacas do estrato 1 , touros do estrato 2 e vacas do estrato 2 . As informações disponíveis para a seleção dos diversos grupos estão apresentadas na Tabela 1. Foi assumido que não se praticava seleção no setor comercial.

O número de parentes com registros nos vários grupos de seleção foi também calculado pelo ZPLAN, com base nos parâmetros reprodutivos e de sobrevivência da Tabela 2.

\section{Parâmetros biológicos e técnicos}

Na Tabela 2 estão apresentados os parâmetros biológicos e técnicos utilizados. Estimativas das taxas de sobrevivência, idade ao primeiro parto, intervalo de partos e vida útil para cada grupo de seleção foram necessárias para a construção da matriz de transmissão de genes. Outros parâmetros, como taxa de parição, número de doses de sêmen produzidas por touro por ano, número de doses de sêmen por prenhez e porcentagem de novilhas disponíveis à seleção, são necessários para o cálculo das proporções dos animais selecionados e das intensidades de seleção. Estes parâmetros foram obtidos de diversas fontes de informação (LEMOS et al., 1996; LÔBO et al., 1999; Dr. C. Schettini e outros criadores, comunicação pessoal).

\section{Pesos econômicos}

Os valores econômicos para mudança unitária em cada característica, apresentados na Tabela 3, foram os de VERCESI FILHO et al. (2000), com exceção do peso ao abate de novilhos, não considerado por aqueles autores. Nesse estudo, os pesos econômicos foram apresentados em equivalentes leite. Para conversão, utilizou-se o preço médio de $\mathrm{R} \$ 0,209$ por kg de leite pago aos produtores de Minas Gerais em 1998 (MADALENA, 2000).

Para estimativa do valor econômico do peso ao abate (PA), o lucro dos machos de abate (Lucro ${ }_{\mathrm{MA}}$ ) foi somado à função de lucro do rebanho leiteiro de VERCESI FILHO et al. (2000):

Lucro total $=$ Lucro $_{\mathrm{MA}}+$ lucro decorrente das outras características, sendo

Lucro $_{\mathrm{MA}}=$ Número de machos de abate $\mathrm{x}$ PA $\mathrm{x}$ (receita por $\mathrm{kg}$ de PA - custo por $\mathrm{kg}$ de PA).

$\mathrm{O}$ número de machos de abate foi considerado igual a 17,39, o número de novilhas no rebanho leiteiro. O preço da arroba do boi $(\mathrm{R} \$ 24,48)$ e o custo médio de produção (R\$19,99/@) foram obtidos do FNP - ANUALPEC 97 (convertidos a reais pela taxa média de US $\$ 1,00=\mathrm{R} \$ 1,20$, dez. 1998). Dessa forma, $_{\text {Lucro }}{ }_{\mathrm{MA}}=[17,39 \mathrm{PA}(0,816-0,6664)]$, e o peso econômico do PA, estimado por intermédio da derivada parcial do lucro em relação à característica $\partial \mathrm{L} / \partial \mathrm{PA}=2,60 \mathrm{R} \$ / \mathrm{kg}$.

Este último valor, assim como os das outras características apresentados por VERCESI FILHO et al. (2000), foi dividido pelo número de vacas naquele estudo $(52,44)$, obtendo-se então os pesos econômicos expressos por unidade da característica e por vaca, apresentados na Tabela 3 . 
LÔBO et al.

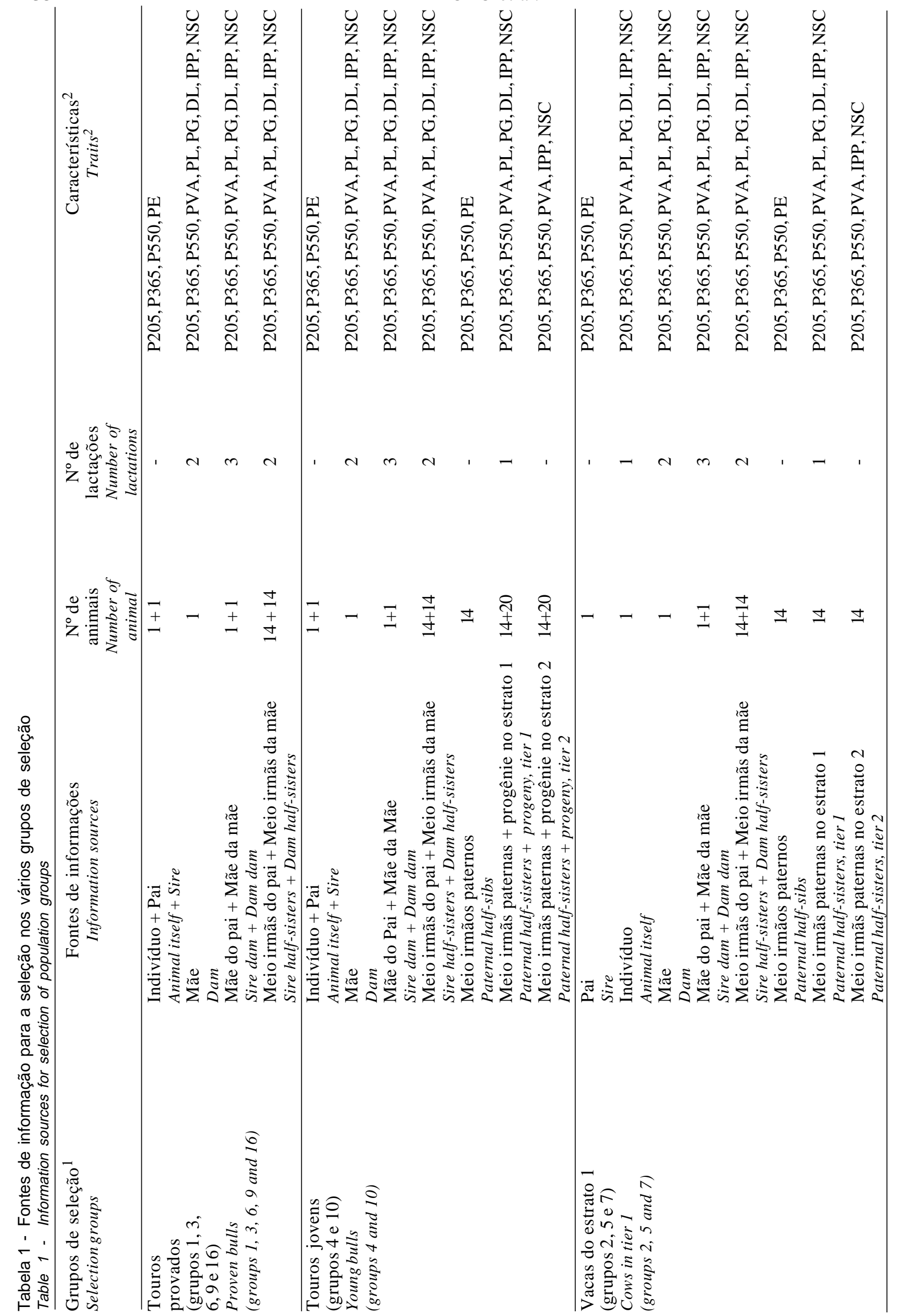


Rev. bras. zootec.

1353

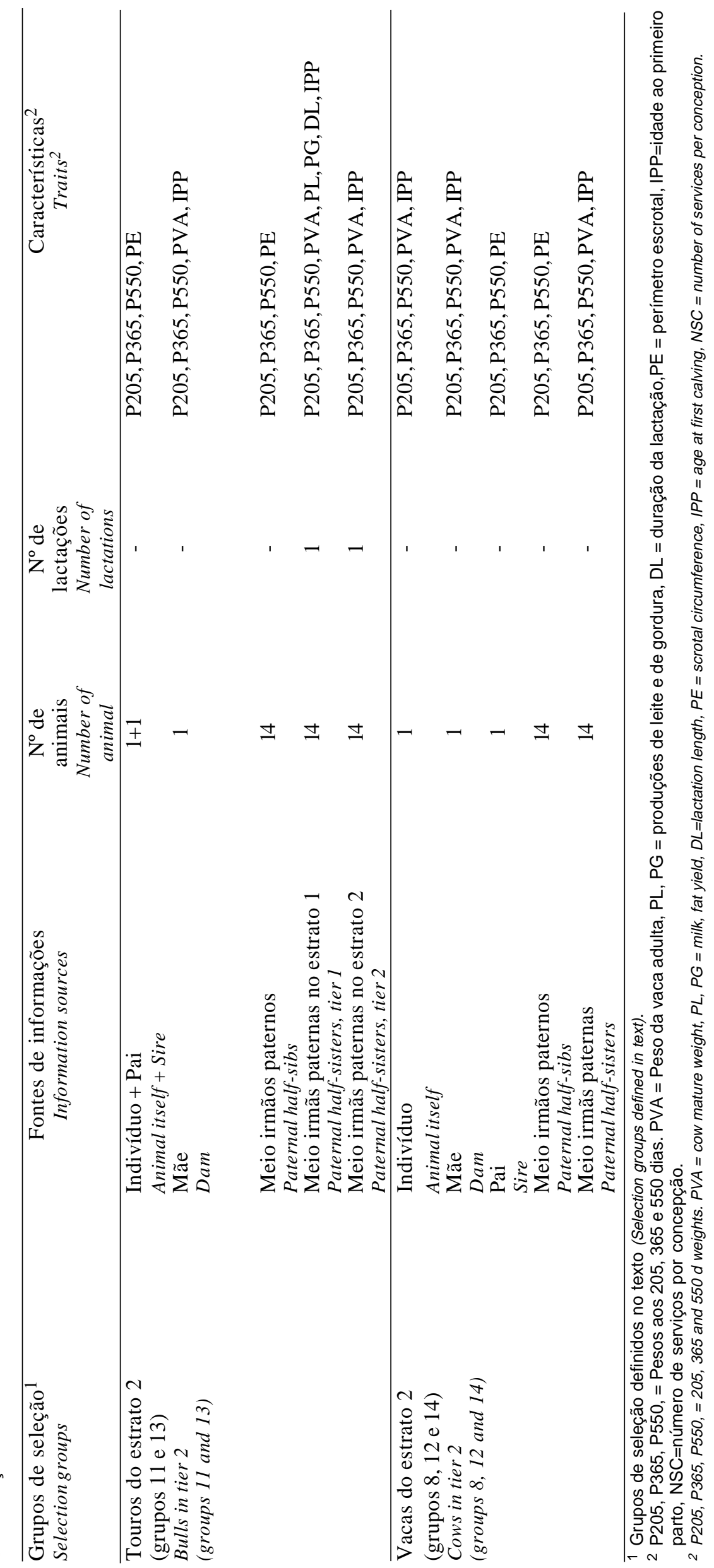




\section{Parâmetros genéticos e fenotípicos}

Os parâmetros genéticos e fenotípicos utilizados estão apresentados na Tabela 3. Os valores de herdabilidade, desvios-padrão fenotípicos e correlações genéticas e fenotípicas foram as médias obtidas por LÔBO et al. (2000), a partir de diversos estudos englobando trabalhos realizados em regiões tropicais, no período 1970 a 1997. Outras fontes de correlações genéticas e fenotípicas foram o estudo de KOOTS et al. (1994) e o
LÔBO et al.

banco de estimativas apresentado no AAABG Genetic Parameters (http://www.gparm.csiro.au/aaabg/). As estimativas de repetibilidade utilizadas referem-se às médias simples calculadas a partir de estudos revisados por LÔBO et al. (2000). A herdabilidade e as correlações utilizadas para fluxo lácteo foram obtidas a partir das médias dos estudos revistos por BLAKE e McDANIEL (1978). O desvio-padrão fenotípico desta característica foi obtido de MADALENA et al. (1989).

Para permitir que as matrizes de correlações genéticas e fenotípicas fossem positivamente definidas,

Tabela 2 - Parâmetros biológicos e técnicos para uma população de bovinos zebus de dupla aptidão Table 2 - Biological and technical parameters for dual purpose zebu cattle population

\begin{tabular}{lc}
\hline & $\begin{array}{c}\text { Vida útil (anos) } \\
\text { Herdlife (years) }\end{array}$ \\
\hline $\begin{array}{l}\text { Touros provados no estrato } 1 \\
\text { Proven bulls in tier } 1\end{array}$ & 2 \\
Touros provados nos estratos 2 e 3 & 4 \\
$\begin{array}{l}\text { Proven bulls in tier } 2 \text { and } 3 \\
\text { Touros jovens }\end{array}$ & 1 \\
Young bulls & \\
Touros dos estratos 2 e 3 & 4 \\
Bulls in tier 2 and 3 & 6 \\
Vacas do estrato 1,2 e 3 & 6 \\
Cows in tier 1,2 and 3 & 3 \\
Vacas mães dos touros do estrato 1 & \\
Dams of bulls in tier 1 &
\end{tabular}

\begin{tabular}{|c|c|}
\hline & $\begin{array}{c}\text { Idade ao nascimento do primeiro filho (anos) } \\
\text { Age at birth of first progeny (years) }\end{array}$ \\
\hline Touros provados & 8 \\
\hline \multicolumn{2}{|l|}{ Proven bulls } \\
\hline Touros jovens & 3 \\
\hline \multicolumn{2}{|l|}{ Young bulls } \\
\hline Touros dos estratos 2 e 3 & 3 \\
\hline \multicolumn{2}{|l|}{ Bulls in tiers 2 and 3} \\
\hline Vacas dos estratos 1,2 e 3 & 3,09 \\
\hline \multicolumn{2}{|l|}{ Cows in tiers 1,2 and 3} \\
\hline & $\begin{array}{l}\text { Sobrevivência e reprodução } \\
\text { Survival and reproduction }\end{array}$ \\
\hline Taxa de sobrevivência anual dos touros e vacas (\%) & 97 \\
\hline \multicolumn{2}{|l|}{ Annual survival rate for bull and cows } \\
\hline Taxa de sobrevivência até desmama (\%) & 93 \\
\hline \multicolumn{2}{|l|}{ Pre-weaning survival rate } \\
\hline Taxa de sobrevivência pós-desmama (\%) & 97 \\
\hline \multicolumn{2}{|l|}{ Post-weaning survival rate } \\
\hline Intervalo de partos das vacas de todos os estratos (anos) & 1,26 \\
\hline \multicolumn{2}{|l|}{ Calving interval of cows in all tiers (years) } \\
\hline Taxa de parição $(\%)$ & 80 \\
\hline Calving rate & \\
\hline
\end{tabular}

Calving rate

Inseminação artificial e seleção involuntária Artificial insemination and involuntary selection

Número de doses de sêmen por touro por ano 20000

Number of semen doses per bull per year

Número de doses por prenhez

Number of semen doses per gestation

Novilhas disponíveis à seleção $(\%)$

95

Heifers calves available for breeding 
Rev. bras. zootec.

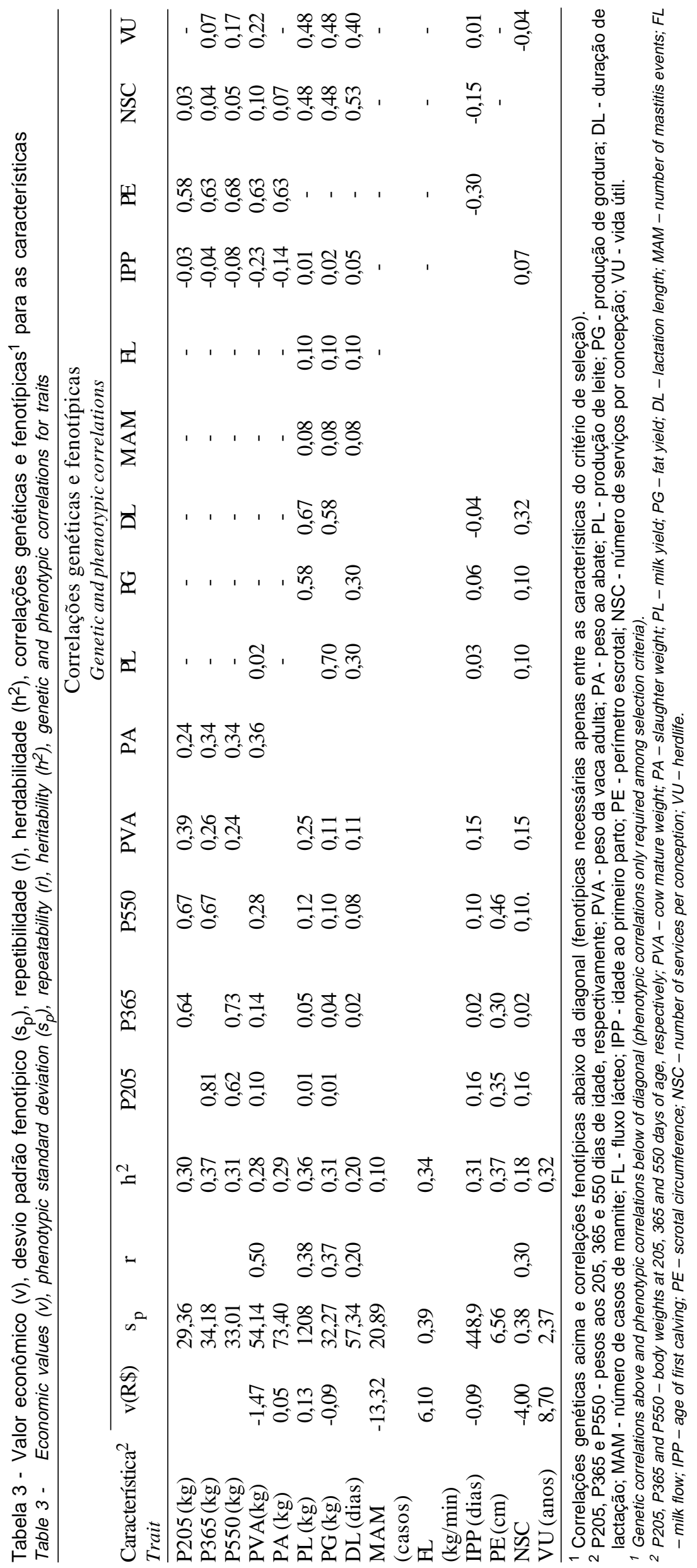


LÔBO et al.

Tabela 4 - Parâmetros de investimento e custos variáveis do programa de melhoramento e tempo médio para a ocorrência dos custos

Table 4 - Breeding program investment and variable costs parameters and average time when costs occur

Parâmetros de investimento

Investment parameters

Período de investimento (anos)

Investment period (years)

Taxa de desconto para receitas (\% a.a.)

Interest rate for returns (\% per year)

Taxa de desconto para custos (\% a.a.)

Interest rate for costs (\% per year)

\begin{tabular}{|c|c|c|}
\hline $\begin{array}{l}\text { Custos variáveis } \\
\text { Variable costs }\end{array}$ & $\mathrm{R} \$$ & $\begin{array}{l}\text { Anos } \\
\text { years }\end{array}$ \\
\hline Custo por fêmea (registro, genealogia, etc.) & 22,20 & 2,00 \\
\hline Cost per cow (identification, pedigree, etc.) & & \\
\hline $\begin{array}{l}\text { Custo de controle de desenvolvimento ponderal } \\
\text { Cost for recording body weights }\end{array}$ & 5,00 & 1,50 \\
\hline Custo de controle leiteiro & 15,50 & 4,27 \\
\hline $\begin{array}{l}\text { Cost for recording dairy traits } \\
\text { Custo de mensuração da idade ao primeiro parto }{ }^{1} \\
\text { Cost for recording age of first calving } 1\end{array}$ & 1,00 & 3,09 \\
\hline $\begin{array}{l}\text { Custo de mensuração do perímetro escrotal } \\
\text { Cost for recording scrotal circumference }\end{array}$ & 2,00 & 1,00 \\
\hline $\begin{array}{l}\text { Custo de mensuração do peso da vaca adulta } \\
\text { Cost for recording mature weight }\end{array}$ & 1,00 & 3,09 \\
\hline $\begin{array}{l}\text { Custo de mensuração do número de serviços por concepção }{ }^{1} \\
\text { Cost for recording number of services per conception }{ }^{1}\end{array}$ & 1,00 & 3,09 \\
\hline $\begin{array}{l}\text { Custo por dose de sêmen } \\
\text { Cost per semen dose }\end{array}$ & 1,80 & - \\
\hline $\begin{array}{l}\text { Custo anual do touro provado em coleta } \\
\text { Annual cost per proven bull in semen collection }\end{array}$ & 3100,00 & - \\
\hline $\begin{array}{l}\text { Custo da coleta dos touros jovens } \\
\text { Cost for young bulls semen collection }\end{array}$ & 750,00 & - \\
\hline
\end{tabular}

${ }^{1}$ Somente processamento dos dados.

1 Data processing only.

Tabela 5 - Custos fixos do programa de melhoramento ${ }^{1}$

Table 5 - Fix costs of breeding program ${ }^{1}$

\begin{tabular}{|c|c|c|}
\hline $\begin{array}{l}\text { Elementos de custo } \\
\text { Cost elements }\end{array}$ & $\begin{array}{c}\text { Valor Mensal }^{2} \\
\text { Monthly value } \\
\text { R\$ }\end{array}$ & $\begin{array}{c}\text { Valor Total } \\
\text { Total value } \\
\text { R } \$\end{array}$ \\
\hline Gerente administrativo & 1842,00 & 94000,00 \\
\hline Manager & & \\
\hline $\begin{array}{l}\text { Secretária de gerência } \\
\text { Secretary }\end{array}$ & 700,00 & 36000,00 \\
\hline $\begin{array}{l}\text { Digitador } \\
\text { Officer to key data }\end{array}$ & 227,00 & 12000,00 \\
\hline $\begin{array}{l}\text { Técnicos (2) } \\
\text { Technical officer }\end{array}$ & 2002,00 & 103000,00 \\
\hline $\begin{array}{l}\text { Processamento de dados }(10 \% \text { dos salários }) \\
\text { Data processing ( } 10 \% \text { of salaries })\end{array}$ & 477,10 & 24000,00 \\
\hline $\begin{array}{l}\text { Viagens ( } 30 \% \text { dos salários) } \\
\text { Travelling (30\% of salaries) }\end{array}$ & 1431,30 & 74000,00 \\
\hline $\begin{array}{l}\text { Comunicação e outras despesas ( } 10 \% \text { dos salários) } \\
\text { Communication and other office ( } 10 \% \text { of salaries) }\end{array}$ & 477,10 & 24000,00 \\
\hline Total & 7156,50 & 367000,00 \\
\hline
\end{tabular}


Rev. bras. zootec.

as estimativas observadas na literatura foram modificadas utilizando o software "bendpdf" (www.boku.ac.at/nuwi/popgen/softbend.htm), com base no procedimento de ESSL (1991) e na teoria desenvolvida por HAYES e HILL (1981).

Parâmetros de investimento e custos

Os parâmetros de investimento e custos assumidos para o programa de seleção estão apresentados na Tabela 4. Os custos variáveis referem-se aos registros de desempenho e pedigree e ocorreram exclusivamente nos grupos dos estratos 1 e 2, em que se originava o melhoramento. Estes custos basearam-se nas taxas de serviço da Associação Brasileira dos Criadores de Zebu (ABCZ, Dr. L. A. Josakhian, comunicação pessoal) e nos custos de alojamento de touros, produção e processamento de sêmen (PECPLAN - ABS, Dr. C. Schetini, comunicação pessoal).

Os custos fixos referem-se aos custos com despesas de uma Associação de Raça e de seu envolvimento com o controle e registro dos animais e de suas produções. Na Tabela 5, está apresentado o modo como foi estimado este custo.

\section{Resultados e Discussão}

Consta da Tabela 6 a resposta genética anual para o objetivo da seleção e para cada característica do objetivo e do critério de seleção, assim como o lucro genético por vaca.

A resposta à seleção para a produção de leite foi alta $(163,95 \mathrm{~kg} / \mathrm{ano})$, superando as tendências genéticas observadas em dados de campo na raça Holandês no Brasil ( $8,43 \mathrm{~kg} / \mathrm{ano})$ e nos Estados Unidos (46,76 kg/ano) (HOURI NETO, 1996) e na raça Gir (VERNEQUE et al., 1996), também no Brasil, indicando que, na prática, os criadores efetuam seleção menos intensa para produção e/ou utilizam programas subótimos. O lucro genético proveniente desta

Tabela 6 - Resposta genética anual e lucro genético por vaca na população Table 6 - Annual genetic responses and genetic profit per cow in the population

\begin{tabular}{|c|c|c|}
\hline $\begin{array}{l}\text { Característica/critério } \\
\text { Trait/criteria }\end{array}$ & $\begin{array}{l}\text { Resposta anual } \\
\text { Annual response }\end{array}$ & $\begin{array}{c}\text { Lucro genético por vaca } \\
\text { Genetic profit per cow } \\
\mathrm{R} \$\end{array}$ \\
\hline $\begin{array}{l}\text { Peso da vaca adulta, } \mathrm{kg} \\
\text { Mature weight, } \mathrm{kg}\end{array}$ & $-2,46$ & 21,84 \\
\hline $\begin{array}{l}\text { Peso ao abate, } \mathrm{kg} \\
\text { Slaughter weight, } \mathrm{kg}\end{array}$ & $-1,28$ & $-0,81$ \\
\hline $\begin{array}{l}\text { Produção de leite, } \mathrm{kg} \\
\text { Milk yield, } \mathrm{kg}\end{array}$ & 163,95 & 20,09 \\
\hline $\begin{array}{l}\text { Produção de gordura, } \mathrm{kg} \\
\text { Fat yield, } \mathrm{kg}\end{array}$ & 2,06 & $-0,18$ \\
\hline $\begin{array}{l}\text { Número de casos de mamite } \\
\text { Number of mastitis events }\end{array}$ & 0,11 & $-1,50$ \\
\hline $\begin{array}{l}\text { Fluxo lácteo, } \mathrm{kg} / \mathrm{min} \\
\text { Milk flow, } \mathrm{kg} / \mathrm{min}\end{array}$ & 0,00 & 0,03 \\
\hline $\begin{array}{l}\text { Idade ao primeiro parto, dias } \\
\text { Age of first calving, days }\end{array}$ & $-0,98$ & $-0,03$ \\
\hline $\begin{array}{l}\text { Número de serviços por concepção } \\
\text { Number of services per conception }\end{array}$ & 0,02 & $-0,06$ \\
\hline $\begin{array}{l}\text { Vida útil, anos } \\
\text { Herdlife, years }\end{array}$ & 0,11 & 0,83 \\
\hline $\begin{array}{l}\text { Objetivo da seleção, } \mathrm{R} \$ \\
\text { Breeding objective, } R \$\end{array}$ & 24,16 & 40,21 \\
\hline $\begin{array}{l}\text { Peso aos } 205 \text { dias de idade, } \mathrm{kg} \\
\text { Weight at } 205 \text { days of age, } \mathrm{kg}\end{array}$ & $-0,75$ & \\
\hline $\begin{array}{l}\text { Peso aos } 365 \text { dias de idade, } \mathrm{kg} \\
\text { Weight at } 365 \text { days of age, } \mathrm{kg}\end{array}$ & $-0,54$ & \\
\hline $\begin{array}{l}\text { Peso aos } 550 \text { dias de idade, } \mathrm{kg} \\
\text { Weight at } 550 \text { days of age, } \mathrm{kg}\end{array}$ & $-0,36$ & \\
\hline $\begin{array}{l}\text { Duração da lactação, dias } \\
\text { Lactation length, days }\end{array}$ & 4,04 & \\
\hline $\begin{array}{l}\text { Perímetro escrotal, } \mathrm{cm} \\
\text { Scrotal circumference, } \mathrm{cm}\end{array}$ & $-0,23$ & \\
\hline
\end{tabular}


1358

Tabela 7 - Lucro genético, custos e valor presente liquido por vaca no programa ${ }^{1}$

Table 7 - Genetic profit, costs and net present value per cow in the program $^{1}$

\begin{tabular}{lc}
\hline Item & $\mathrm{R} \$$ \\
\hline $\begin{array}{l}\text { Custos fixos por vaca } \\
\text { Custos variáveis por vaca }\end{array}$ & 3,36 \\
$\begin{array}{l}\text { Variable costs per cow } \\
\text { Custos totais por vaca }\end{array}$ & 8,64 \\
Overall costs per cow & 12,00 \\
\hline
\end{tabular}

Lucro genético total por vaca $\quad 40,21$

Overall genetic profit per cow

Valor presente liquido por vaca 28,21

Net present value per cow

${ }^{1}$ Intervalo de gerações $=6,85$ anos (Generation interval $=6.85$ years).

característica foi o segundo na ordem de importância, depois do lucro genético proveniente da diminuição do peso da vaca adulta. Já BALAINE et al. (1981) verificaram que a variação na produção de leite foi a característica mais importante para o lucro em sistema leiteiro nos Estados Unidos.

A mudança genética negativa no peso da vaca adulta $(-2,46 \mathrm{~kg})$ resultou do alto custo relativo da mantença no estudo que forneceu os valores econômicos. Já GROEN (1989), na Holanda, relatou que o acréscimo do consumo de forragens de um animal decorrente do aumento no peso corporal adulto promoveu pequeno efeito negativo sobre a eficiência econômica, mas naquele país, como em outros da Europa, o valor econômico relativo da carne é muito alto, ao contrário da situação aqui estudada. O lucro genético proveniente da diminuição do peso da vaca ( $R \$ 21,84$, Tabela 6 ) foi elevado e superou inclusive o lucro genético para produção de leite ( $\mathrm{R} \$ 20,09)$. Este lucro genético possivelmente decorreu da diminuição nas necessidades de mantença, em conseqüência da seleção para menor peso das fêmeas. Entretanto, na Holanda, GROEN (1989) estimou pequenas mudanças no peso econômico para peso da vaca adulta, quando aumentou ou reduziu em $20 \%$ o preço pago pelo leite. Se o preço pago pelo leite no Brasil fosse maior que o atual, possivelmente haveria redução no peso relativo dos custos de mantença e, conseqüentemente, da importância do peso da vaca adulta.

Pode ser visto na Tabela 6 que a resposta para peso ao abate foi negativa, indicando que a seleção atuaria contra esta característica. Este resultado, à primeira vista surpreendente, pode ser explicado pelo alto valor econômico negativo do peso da vaca e pela correlação genética positiva desta característica com o peso de abate. Assim, seleção para peso ao abate conduz a aumento do tamanho corporal das matrizes, elevando o consumo de alimentos, de forma que o aumento dos custos com a manutenção das vacas não seria compensado pelos ganhos advindos do incremento do peso ao abate. Dessa forma, quando o programa é otimizado, a seleção é direcionada para a redução no peso da vaca adulta, com diminuição correlacionada no peso ao abate. Deve ser notado que o aumento projetado no consumo das matrizes está baseado na suposição de que os requisitos para mantença não seriam afetados pela seleção. Entretanto, a validade desta suposição ficou questionada pela verificação de HERD (1995) de que a seleção para peso, de fato, reduziu os requisitos de energia para mantença por kg de peso vivo em vacas Angus. Este é mais um aspecto que deve ser mais pesquisado, especialmente nas raças brasileiras.

A produção de gordura, apesar de ter valor econômico negativo, decorrente da baixa remuneração deste componente (MADALENA, 2000), teve resposta genética positiva, o que poderia ser explicado pela sua alta correlação genética com a produção de leite $\left(\mathrm{r}_{\mathrm{g}}=0,58\right.$, Tabela 3$)$. Da mesma forma, a resposta desfavorável para número de serviços por concepção poderia ser explicada pelas correlações genéticas desta característica com a idade ao primeiro parto $\left(r_{g}=-0,15\right)$ e a produção de leite $\left(r_{g}=0,48\right)$. A resposta desfavorável para número de casos de mamite poderia ser explicada pelas correlações genéticas positivas entre esta característica e a produção de leite e de gordura (Tabela 3).

A reduzida mudança no fluxo lácteo $(<0,001 \mathrm{~kg})$ min/ano, Tabela 6) pode ter sido decorrente da baixa variância desta característica, associada às pequenas correlações genéticas assumidas entre esta e as características de produção de leite, gordura e duração de lactação (Tabela 3).

Houve pequena redução na idade ao primeiro parto (-0,98 dias/ano) e lucro genético negativo de $\mathrm{R} \$ 0,03$ por vaca, devido à seleção para esta característica. Apesar de o valor econômico para idade ao primeiro parto ter sido negativo, sua redução não conduziu a lucro genético favorável. A mudança genética para cada característica é a soma das mudanças em cada grupo de seleção ponderadas pelo peso econômico da característica. Em alguns grupos de seleção (touros e vacas do estrato 3 , touros jovens, vacas do estrato 1 e touros do estrato 2 ), a resposta genética para idade ao primeiro parto foi desfavorável, 
porém favorável nos outros grupos, conduzindo, assim, no programa como um todo, à redução na idade ao primeiro parto. Entretanto, para gerar o lucro genético total, o produto da mudança genética e do peso econômico é multiplicado pelo número de expressões descontadas. Este número foi maior nos grupos mais baixos da estrutura de população (setor comercial). Dessa forma, o lucro genético nos grupos em que a mudança genética foi favorável (touros provados e vacas do estrato 2) foi multiplicado por um menor número de expressões descontadas. Assim, na soma do lucro genético de cada grupo para gerar o lucro genético total, a contribuição dos grupos em que o lucro genético foi desfavorável superou a contribuição dos grupos com lucro genético favorável, o que conduziu ao lucro genético total negativo, embora pequeno, para a idade ao primeiro parto.

A mudança genética de 0,11 anos para a vida útil (Tabela 6), ocorrida principalmente devido à sua associação com as características de crescimento e produção de leite (Tabela 3 ), conduziu à contribuição positiva para o lucro genético $(\mathrm{R} \$ 0,83)$.

A resposta genética anual de $\mathrm{R} \$ 24,16$ para o objetivo da seleção foi estimada dividindo a reposta por geração pelo intervalo médio de gerações. O lucro genético total por vaca $(\mathrm{R} \$ 40,21)$, considerando toda a população de 85.000 vacas, foi obtido somando-se o lucro genético por vaca de cada um dos grupos de seleção. Subtraindo os custos, chegou-se ao valor presente líquido por vaca gerado pelo programa de melhoramento ( $\mathrm{R} \$ 28,21)$. NITTER et al. (1994), avaliando um esquema de seleção para corte na Austrália, observaram valor presente líquido por vaca de $\mathrm{A} \$ 6,81$.

Os custos e o valor presente líquido por vaca e o intervalo de gerações, considerando todo o programa de seleção avaliado no período de 30 anos, estão apresentados na Tabela 7. A alta resposta genética para o objetivo indica que a seleção por meio do teste de progênie e a utilização de touros provados podem ser bastante eficientes; acima de $70 \%$ do lucro genético, equiivaleu ao valor presente líquido, o que pode ser considerado bastante satisfatório. A reposta econômica deste estudo superou a estimada para outros programas de melhoramento de bovinos. Assim, ressalvando as diferenças dos sistemas de produção e das economias envolvidas, pode-se citar que, no Reino Unido, HILL (1971) observou retorno acima de $15 \%$ para esquemas de seleção para corte dentro do rebanho leiteiro ou dentro das raças de corte usadas como fontes de touros para cruzamento, e GRASER et al. (1994) observaram retorno ao investimento na ordem de 15 a $20 \%$ para esquemas de seleção para bovinos de corte na Austrália.
O intervalo de gerações observado neste estudo (6,85 anos) foi alto, mas não superou o observado por PEIXOTO et al. (1998) em um rebanho Gir (8,03 anos).

Os altos valores econômicos para a mudança unitária das características incluídas no objetivo da seleção explicam o alto lucro genético observado para o esquema de seleção proposto para os animais de dupla aptidão. O pequeno número de animais em que as características foram mensuradas, a partir dos quais ocorre o melhoramento genético, explica os baixos custos para o programa, uma vez que estes foram diluídos em todos os estratos da população. Estes fatores podem também explicar o grande valor presente líquido observado. Em adição, deve-se ressaltar a importância da inseminação artificial como propagadora dos genes dos animais melhoradores para toda a população comercial.

Os pesos econômicos utilizados foram estimados pela derivada parcial da função de lucro $(\mathrm{L})=$ receitas (R) - custos (C), com respeito a cada característica $\left(\partial \mathrm{L} / \partial \mathrm{x}_{\mathrm{i}}\right)$. Os custos fixos de produção, neste caso, são desconsiderados (desaparecem no processo de derivação), o que poderia causar sobrevalorização do ganho genético, sendo mais correto obter os pesos econômicos como $\partial(\mathrm{R} / \mathrm{C}) / \partial \mathrm{x}_{\mathrm{i}}$ (SMITH et al., 1986), o que, entretanto, não foi possível, já que não se dispunha dos custos fixos para recria e engorda. Entretanto, ambos os métodos produziram pesos econômicos semelhantes (VERCESI FILHO et al., 2000), de forma que a aproximação utilizada se considera satisfatória. PONZONI (1988) também obteve pesos econômicos semelhantes com diferentes formas de expressar o lucro.

Os resultados obtidos são aplicáveis apenas aos sistemas de produção considerados. Em outros sistemas com diferentes parâmetros econômicos ou zootécnicos, os ganhos genéticos e o lucro do programa de melhoramento seriam provavelmente diferentes, sendo conveniente pesquisar a eficiência do programa em outras circunstâncias, o que requer disponibilidade de dados de custos de produção e receitas em outras fazendas.

\section{Conclusões}

A seleção para bovinos zebus de dupla aptidão, com a realização do teste de progênie dos touros jovens, promoveu favoráveis ganhos e lucro genéticos para o sistema de produção considerado.

$\mathrm{O}$ alto lucro genético possível de ser alcançado com a seleção, justificou os custos relacionados a esta atividade, principalmente porque estes custos 
foram efetuados em um número de animais bastante reduzido, em comparação à população total que se beneficiaria com o melhoramento.

As características incluídas no objetivo da seleção que mais contribuíram para as respostas genéticas e econômicas foram peso da vaca adulta e produção de leite, indicando ser importante selecionar animais de maior produção leiteira e com menor requerimento para mantença.

\section{Agradecimento}

Ao Prof. G. Nitter, Universidade de Hohehein, pelas orientações para uso do programa ZPLAN, e aos Drs. L. A. Josakhian (ABCZ) e Cláudio Schetini (PECPLAN - ABS), pelas informações concedidas.

\section{Referências Bibliográficas}

BALAINE, D.S., PEARSON, R.E., MILLER, R.H. 1981. Profit functions in dairy cattle and effect of measures of efficiency and prices. J. Dairy Sci., 64(1):87-95.

BLAKE, R.W., McDANIEL, B.T. 1978. Relationships among rates of milk flow, machine time, udder conformation, and managemental aspects of milking efficiency: a review. $J$. Dairy Sci., 61:363-378.

ESSL, A. 1991. Choice of an appropriate bending factor using prior knowledge of the parameters. J. Anim. Breed. Genet., 108:89-101.

FERREIRA, J.J., FERREIRA, M.B.D. Sistema de produção de leite da EPAMIG. Desempenho por grupo racial e custo da produção de leite. Brasil.In: ENCONTRO DE PRODUTORES DE GADO LEITEIRO $\mathrm{F}_{1}, 2,1998$, Belo Horizonte. Anais...Belo Horizonte, UFMG, 1998, p.19-28.

FNP - Consultoria \& Comércio. ANUALPEC 97. São Paulo-SP, 1997. Fone (011) 8281414.

GRASER, H.U., NITTER, G., BARWICK, S.A., 1994. Evaluation of advanced industry breeding schemes for Australian beef cattle. II. Selection on combinations of growth, reproduction and carcase criteria. Aust. J. Agric. Res., 45:1657-1669.

GROEN, A.F. 1989. Economic values in cattle breeding. I. Influences of production circumstances in situations without output limitations. Lvstck. Prod. Sci., 22:1-16.

HAYES, J.F., HILL, W.G., 1981. Modification of estimates of parameters in the construction of genetic selection indices ('bending'). Biometrics, 37:483-493.

HERD, R.M. 1995. Effect of divergent selection for yearling growth rate on the maintenance feed requirements of mature Angus cows. Lvstck. Prod. Sci., 41:39-50.

HILL, W.G. 1971. Investment appraisal for national breeding programmes. Anim. Prod., 13:37-50.

HOURI NETO, M. Interação genótipo-ambiente e avaliação genética de reprodutores da raça Holandesa, usados no Brasil e nos Estados Unidos da América: Belo Horizonte, MG: Escola de Veterinária - UFMG, 1996, 204p. Tese (Doutorado em Ciência Animal) - Universidade Federal de Minas Gerais, 1996.

JOSAKHIAN, L.A. Taxas de serviços da Associação Brasileira dos Criadores de Zebu. Uberaba, 1998. (Comunicação Pessoal).

KARRAS, K. 1984.ZPLAN - EDV- Programm zur Optimierung der Zuchtplanung bei landwirtschaftlichen Nutztieren: University Hohenheim: Hohenheim.

KARRAS, K., NIEBEL, E., NITTER, G., BARTENSCHLAGER, H. 1993. ZPLAN- a PC computer program to optimise livestock selection programs. Hohenheim: University Hohenheim. 36p.

KOOTS, K.R., GIBSON, J.P., WILTON, J.W., 1994. Analyses of published genetic parameter estimates for beef production traits. 2. Phenotypic and genetic correlations. Anim. Breed. Abst., 62(11):825-852.

LEMOS, A.M., TEODORO, R.L., MADALENA, F.E., 1996. Comparative performance of six Holstein-Friesian x Guzera grades in Brazil. 9. Stayability, herd life and reasons for disposal. Braz. J. Genet., 19(2):259-264.

LÔBO, R.N.B. Programas de seleção para bovinos zebus de dupla aptidão: Belo Horizonte, MG: Escola de Veterinária UFMG, 1999, 118p. Tese (Doutorado em Ciência Animal) - Universidade Federal de Minas Gerais, 1999.

LÔBO, R.N.B., MADALENA, F.E., VIEIRA, A.R. 2000. Means of published genetic parameter estimates for cattle raised on tropical climate. Anim. Breed. Abstr., 68(6):433-462.

MADALENA, F.E. 2000. Valores econômicos para a seleção de gordura e proteína do leite. Rev. bras. zootec., 29(3):678-684.

MADALENA, F.E., TEODORO, R.L., NOGUEIRA, J.D. et al. 1989. Comparative performance of six Holstein-Friesian $\mathrm{x}$ Guzera crossbreed groups in Brazil. 4 Rate of milk flow, ease of milking and temperament. Rev. Brasil. Genet., 12(1):39-51.

NIEBEL, E., FEWSON, D. 1988. Population sector models: cattle breeding programs. In: KORVER, S., ARENDONK, J.A.M. (Eds.) Modeling of livestock production systems. Dordrecht: Kluwer Academic Publishers. p.182-191.

NITTER, G., GRASER, H.U., BARWICK, S.A., 1994. Evaluation of advanced industry breeding schemes for Australian beef cattle. I. Method of evaluation and analysis for an example population structure. Aust. J. Agric. Res., 45:1641-1656.

PEIXOTO, M.G.C.D., LÔBO, R.N.B., PENNA, V.M. Intervalo de gerações e diferencial de seleção em um rebanho Gir leiteiro. In: SIMPÓSIO NACIONAL DA SOCIEDADE BRASILEIRA DE MELHORAMENTO ANIMAL, 2, 1998, Uberaba. Anais...Uberaba: SBMA, 1998, p.403-404.

PONZONI, R.W. Accounting for both income and expense in the development of breeding objectives. In: CONFERENCE AUSTRALIAN OF ASSESSMENT IN ANIMAL BREEDING AND GENETIC, 7, 1988, Melborne. Proceedings...Melborne, 1988. p.55-66.

SCHETTINI, C. Custos de alojamento de touros, produção e processamento de sêmen. Uberaba, 1998. (Comunicação Pessoal).

SEBRAE-MG, 1996. Diagnóstico da pecuária leiteira do Estado de Minas Gerais: relatório de pesquisa/SEBRAE-MG; FAEMG - Belo Horizonte: SEBRAE-MG, 1996. 102p.:tb.

SMITH, C., JAMES, J.W., BRASCAMP, E.W., 1986. On the derivation of economic weights in livestock improvement. Anim. Prod., 43:545-551.

VERCESI FILHO, A.E., MADALENA, F.E., FERREIRA, J.J.et al. 2000. Pesos econômicos para seleção de gado de leite. Rev bras. zootec., 29(1)145:152.

VERNEQUE, R.S., FERREIRA, W.J., TEODORO, R.L., MARTINEZ, M.L. Tendência genética da produção de leite em rebanhos da raça "Gir leiteiro". In: REUNIÃO ANUAL DA SOCIEDADE BRASILEIRA DE ZOOTECNIA, 33, 1996, Fortaleza, CE. Anais... Fortaleza: SBZ, 1996, p.30-32.

Recebido em: 22/06/99 Aceito em: 03/04/00 